\title{
Hubungan Pengetahuan Ibu Hamil TM III tentang Tanda Bahaya Kehamilan dengan Pemanfaatan Buku KIA
}

\author{
Fina Alfiana, Yuniasih Purwaningrum, Ida Prijatni \\ ${ }^{1)}$ Program Studi Kebidanan Jember, Politeknik Kesehatan Kemenkes Malang, finaalfiana8@ gmail.com \\ ${ }^{2)}$ Program Studi Kebidanan Jember, Politeknik Kesehatan Kemenkes Malang, \\ yunipurwaningrum268@gmail.com \\ ${ }^{3)}$ Program Studi Kebidanan Jember, Politeknik Kesehatan Kemenkes Malang, ida.prijatni59@gmail.com
}

\begin{abstract}
ABSTRAK
Saat ini banyak ibu hamil kurang memahami pentingnya buku KIA. Buku KIA sering diasumsikan sebagai kartu kontrol yang harus dibawa oleh ibu hamil. Dengan banyaknya informasi yang tertuang didalam buku KIA berdampak isi buku KIA kurang diterapkan oleh ibu hamil. Tujuan penelitian untuk mengetahui hubungan antara pengetahuan bumil TM III tentang tanda bahaya kehamilan dengan pemanfaatan buku KIA. Desain penelitian ini menggunakan probability sampling dengan cara cluster sampling. Data diambil dari kuisioner yang diberikan kepada bumil TM III. Subjek penelitian yaitu bumil TM III, data dianalisis dengan uji spearman rank. Penelitian ini melibatkan 62 bumil TM III. Hasilnya 19 responden (30,6\%) berpengetahuan baik, terinci 15 responden (24,4\%) memanfaatkan buku KIA dan 4 responden (6,5\%) kurang memanfaatkan buku KIA. Sedangkan, 21 responden (33,9\%) yang berpengetahuan cukup, terinci 11 responden (17,7\%) memanfaatkan buku KIA dan 10 responden $(16,1 \%)$ kurang memanfaatkan buku KIA. Selanjutnya, 22 responden (35,5\%) yang berpengetahuan kurang, menunjukkan 16 responden (25,8\%) memanfaatkan buku KIA dan 6 responden (25,8\%) kurang memanfaatkan buku KIA. Hasil uji spearman rank diperoleh $\rho$ value 0,764 $>\alpha=0,05$. Kesimpulannya tidak ada hubungan antara pengetahuan bumil TM III tentang tanda bahaya kehamilan dengan pemanfaatan buku KIA. Sehingga penting pemahaman buku KIA bagi bumil TM III untuk mendeteksi tanda bahaya kehamilan agar segera ditangani dengan cepat dan tepat..
\end{abstract}

Kata Kunci : Pengetahuan, Ibu Hamil, Buku KIA

\section{ABSTRACT}

At this time, many pregnant women don't understand the importance of KIA Books. KIA books are often assumed to be a control card that must carry. But too much of information contained has an impact KIA books being less applied by pregnant woman. The purpose of this study was to determine the relationship between knowledge of pregnant women TM III with danger signs of pregnancy use of KIA books. This research design uses probability sampling by means of cluster sampling. The data were taken from a questionnaire given by pregnant women TM III. Research subject is pregnant women with TM III, data were analyzed by the spearman rank test. This study involved 62 pregnant women TM III. The result is 19 respondents (30.6\%) have good knowledge, in detail 15 respondents (24.4\%) use KIA books and 4 respondents (6.5\%) didn't use KIA books. Meanwhile, 21 respondents (33.9\%) were knowledgeable enough, in detail 11 respondents (17.7\%) used KIA books and 10 respondents (16.1\%) didn't use KIA books. Then, 22 respondents (35.5\%) had less knowledge, indicating that 16 respondents (25.8\%) used KIA books and 6 respondents (25.8\%) didnt use KIA books. Spearman rank test results obtained value 0.764 > =0.05. In conclusion, there is no relationship between the knowledge of pregnant women TM III about the danger signs of pregnancy with the use of the KIA books. So it is important to understand the KIA books for pregnant women with TM III to detect the danger signs of pregnancy so that they can be handled quickly and appropriately.

Keywords : Knowledge, Pregnant mother, KIA books

* Yuniasih Purwaningrum, Program Studi Kebidanan Jember, Politeknik Kesehatan Kemenkes Malang, Kampus 1 Jember Polkesma, e-mail : yunipurwaningrum268@gmail.com, HP.081336432511

\section{PENDAHULUAN}

Buku kesehatan ibu dan anak (buku KIA) merupakan buku yang berisi tentang catatan kesehatan ibu mulai dari ibu hamil, ibu melahirkan sampai ibu nifas, dan berisi catatan kesehatan anak, mulai dari bayi baru lahir sampai dengan anak berusia 6 tahun. ${ }^{1}$ Pada pelaksanaannya masih banyak ibu hamil yang belum mengetahui dan memahami apa isi dari buku KIA, sehingga mereka juga tidak 
menerapkan informasi kesehatan yang ada dalam buku KIA. ${ }^{2}$

Buku KIA lebih dikenal masyarakat sebagai buku berwarna pink (merah muda) yang diterima langsung oleh ibu atau keluarga dari tempat pelayanan kesehatan. ${ }^{3}$ Mereka berasumsi buku ini hanya sebagai kartu kontrol yang harus dibawa saat periksa, tidak banyak ibu hamil yang mau membaca dan menerapkan apa yang ada di dalam buku KIA. Salah satu penyebabnya yaitu kurangnya pemahaman ibu hamil tentang isi dari buku KIA dan rendahnya minat baca masyarakat Indonesia yang sangat memprihatinkan, Berdasarkan studi "Most Littered Nation In the World" yang dilakukan oleh Central Connecticut State Univesity pada Maret 2016 lalu Indonesia menduduki peringkat 60 dari 61 negara.

Ibu hamil di Indonesia yang mempunyai buku KIA sebesar 80,8\%, namun yang mengetahui isi dari buku KIA itu sendiri hanya 40,4\%. ${ }^{4}$ Hasil observasi pada buku KIA terhadap 5 komponen $\mathrm{P} 4 \mathrm{~K}$, yang meliputi penolong persalinan, dana persalinan, kendaraan/ ambulan desa, metode KB, donor darah, menunjukkan bahwa pada komponen penolong persalinan sebesar $35,4 \%$, dana persalinan sebesar 17,3\%, kendaraan/ambulans desa sebesar $14,4 \%$, metode KB pasca salin sebesar $19,2 \%$ dan $12,1 \%$ untuk isian sumbangan darah. Kelengkapan isian pada semua komponen sebesar $10,7 \%$ dan $64,0 \%$ tidak ada isian.

Kepemilikan buku KIA di Jawa Timur adalah $48,4 \%$, namun dari ibu yang memiliki buku KIA tersebut yang dapat menunjukkan buku KIA adalah $22,3 \%$, sedangkan yang tidak dapat menunjukkan buku KIA adalah 26,1\%, karena buku mereka disimpan oleh orang lain, untuk ibu yang tidak memiliki buku KIA cukup besar, yakni 51,6\%. ${ }^{5}$

Jumlah ibu hamil di Kabupaten Jember yakni 40.224 orang dan sudah semua ibu hamil tersebut memiliki buku KIA, dengan kata lain kepemilikan buku KIA di Kabupaten Jember sudah $100 \%$. Namun dari semua ibu hamil tersebut hanya $78,59 \%$ yang menggunakan buku KIA nya hingga trimester akhir, sebesar 20,08\% ibu sudah tidak menggunakan buku KIA dan kehamilannya lepas dari pemantauan petugas kesehatan. ${ }^{6}$

Dampak dari pemanfaatan buku KIA yang kurang baik salah satunya yaitu tidak terdeteksinya komplikasi kehamilan oleh petugas kesehatan, karena tidak semua ibu hamil yang melakukan kunjungan pertama pelayanan antenatal meneruskan hingga kunjungan ke-4 pada triwulan 3. Dampak lainnya yakni tidak semua balita dapat diketahui status imunisasinya, hal ini disebabkan karena ibu lupa anaknya sudah diimunisasi atau belum, ibu lupa berapa kali sudah diimunisasi, ibu tidak mengetahui secara pasti jenis imunisasi, catatan dalam KMS/ buku KIA tidak lengkap/tidak terisi, tidak dapat menunjukkan karena hilang atau tidak disimpan oleh ibu. ${ }^{4}$

Salah satu upaya yang selama ini telah dilaksanakan oleh tenaga kesehatan yakni melakukan penyuluhan pada ibu hamil dan keluarga tentang manfaat buku KIA. Agar petugas kesehatan dapat memberikan penyuluhan tentang buku KIA, terampil dalam mengisi buku KIA dan juga dapat memahami isi buku KIA, Departemen Kesehatan yang bekerjasama dengan Japan International Cooperation Agency (JICA) dalam "The Project for ensuring maternal and child health services with the $\mathrm{MCH}$ handbook, phase II" menyusun Orientasi Penggunaan Buku KIA untuk Petugas Kesehatan. ${ }^{7}$

Selain itu, agar ibu dan semua keluarga dapat menggunkan buku KIA, para pengambil keputusan ditingkat provinsi dan kabupaten/kota dibekali pedoman umum manajemen penerapan Buku KIA. Pedoman ini berisi tentang informasi mengenai pengelolan Buku KIA, langkah langkah kegiatan dan upaya untuk menjamin kelangsungan penggunan buku KIA oleh masyarakat agar dapat diterapkan sesuai dengan standart serta sampai pada sasaran yang dituju. ${ }^{3}$

\section{METODOLOGI}

Pada penelitian ini menggunakan desain penelitian analitik korelasi dengan pendekatan crossectional. Penelitian ini mengkorelasikan antara faktor resiko dengan cara menggunakan pengukuran dan pengamatan secara bersamaan dalam sekali waktu (point time approach). 
Pengumpulan data pada penelitian ini dengan menggunakan data primer. Populasinya adalah semua ibu hamil dengan usia kehamilan 28 - 40 minggu di Wilayah Puskesmas Sumbersari yang memiliki buku KIA pada bulan November 2018 - Januari 2019 yaitu sejumlah 73 orang. Sampel dihitung dengan menggunakan rumus Slovin dan didapatkan hasil sampel yaitu 62 ibu hamil yang memiliki buku KIA. Penelitian ini menggunakan teknik cluster sampling yaitu teknik penentuan sampel yang dilakukan dengan membagi populasi studi menjadi beberapa bagian (blok) sebagai cluster secara acak dan dilakukan pengambilan sampel pada cluster tersebut. Alat ukur yang digunakan pada penelitian ini adalah menggunakan lembar kuisioner. Analisa data menggunakan spearman rank

\section{HASIL DAN PEMBAHASAN}

Tabel 1. Distribusi frekuensi responden berdasarkan pekerjaan

\begin{tabular}{ccc}
\hline Pekerjaan & Jumlah & Persentase (\%) \\
\hline Tidak Bekerja & 52 & 83,9 \\
PNS & 1 & 1,6 \\
Wiraswasta & 9 & 14,5 \\
\hline Jumlah & 62 & 100
\end{tabular}

Menunjukkan bahwa responden hampir seluruhnya $(83,9 \%)$ tidak bekerja.

Tabel 2. Distribusi frekuensi responden berdasarkan sasaran umur

\begin{tabular}{ccc}
\hline Umur & Jumlah & Persentase (\%) \\
\hline$<20$ tahun & 2 & 3,2 \\
$20-35$ & 57 & 91,9 \\
$>35$ & 3 & 4,8 \\
\hline Jumlah & 62 & 100
\end{tabular}

Menunjukkan bahwa responden hampir seluruhnya $(91,9 \%)$ berada dalam usia reproduksi.

Tabel 3. Distribusi frekuensi responden berdasarkan pendidikan formal

\begin{tabular}{ccc}
\hline Pendidikan & Jumlah & Persentase (\%) \\
\hline SD & 13 & 21,0
\end{tabular}

\begin{tabular}{|c|c|c|}
\hline Pendidikan & Jumlah & Persentase (\%) \\
\hline SMP & 8 & 12,9 \\
\hline SMA & 34 & 54,8 \\
\hline $\begin{array}{l}\text { Perguruan } \\
\text { Tinggi }\end{array}$ & 7 & 11,3 \\
\hline Jumlah & 62 & 100 \\
\hline
\end{tabular}
sebagian besar $(54,8 \%)$ berpendidikan SMA.

Tabel 4. Distribusi frekuensi responden berdasarkan paritas ibu

\begin{tabular}{ccc}
\hline Paritas & Jumlah & Persentase (\%) \\
\hline Primigravida & 24 & 38,7 \\
Multigravida & 38 & 61,3 \\
\hline Jumlah & 62 & 100
\end{tabular}

Menunjukkan bahwa responden sebagian besar $(61,3 \%)$ adalah multigravida.

Tabel 5. Distribusi Pengetahuan ibu hamil TM III tentang tanda bahaya kehamilan

\begin{tabular}{ccc}
\hline $\begin{array}{c}\text { Pengetahuan ibu hamil } \\
\text { TM III tentang tanda } \\
\text { bahaya kehamilan }\end{array}$ & Jumlah & $\begin{array}{c}\text { Persentase } \\
(\%)\end{array}$ \\
\hline Baik & 19 & 30,6 \\
Cukup & 21 & 33,9 \\
Kurang & 22 & 35,5 \\
\hline Jumlah & 62 & 100 \\
\hline
\end{tabular}

Menunjukkan bahwa hampir setengah responden berpengetahuan kurang, yaitu 22 responden $(35,5 \%)$.

Tabel 6. Distribusi pemanfaatan buku KIA di

\begin{tabular}{lcc}
\hline $\begin{array}{c}\text { Pemanfaatan } \\
\text { Buku KIA }\end{array}$ & Jumlah & $\begin{array}{c}\text { Persentase } \\
(\%)\end{array}$ \\
\hline Memanfaatkan & 42 & 67,7 \\
$\begin{array}{c}\text { Kurang } \\
\text { Memanfaatkan }\end{array}$ & 20 & 32,3 \\
\hline Jumlah & 62 & 100 \\
\hline Menunjukkan & bahwa sebagian besar \\
$(67,7 \%)$ responden & telah memanfaatkan buku \\
KIA. &
\end{tabular}


Tabel 7. Tabel silang Hubungan antara

Pengetahuan Bumil TM III tentang tanda bahaya kehamilan dengan pemanfaatan buku KIA

\begin{tabular}{|c|c|c|c|c|c|c|c|}
\hline \multirow{3}{*}{$\begin{array}{l}\text { Pengetahuan } \\
\text { Ibu hamil } \\
\text { TM III } \\
\text { tentang tanda } \\
\text { bahaya } \\
\text { kehamilan }\end{array}$} & \multicolumn{6}{|c|}{ Pemanfaatan buku KIA } & \multirow[b]{2}{*}{$\begin{array}{c}\text { Spear } \\
\text { man } \\
\text { Rank }\end{array}$} \\
\hline & \multicolumn{2}{|c|}{$\begin{array}{l}\text { Meman } \\
\text { faatkan }\end{array}$} & \multicolumn{2}{|c|}{$\begin{array}{c}\text { Kurang } \\
\text { Memanfaat } \\
\text { kan }\end{array}$} & \multicolumn{2}{|c|}{ Jumlah } & \\
\hline & $\mathrm{N}$ & $(\%)$ & $\mathrm{N}$ & $(\%)$ & $\mathrm{N}$ & $(\%)$ & \multirow{5}{*}{0,764} \\
\hline Baik & 15 & 24,2 & 4 & 6,5 & 19 & 30,6 & \\
\hline Cukup & 11 & 17,7 & 10 & 16,1 & 21 & 33,9 & \\
\hline Kurang & 16 & 25,8 & 6 & 9,7 & 22 & 35,5 & \\
\hline Total & 42 & 67,7 & 20 & 32,3 & 62 & 100 & \\
\hline
\end{tabular}

Hasil uji spearman rank diperoleh $\rho$ value $0,764>\alpha=0,05$. Berarti H0 diterima dan H1 ditolak. Kesimpulannya tidak ada hubungan antara pengetahuan bumil TM III tentang tanda bahaya kehamilan dengan pemanfaatan buku KIA.

Berdasarkan hasil penelitian yang telah dilakukan dengan 62 responden, terdapat responden yang berpengetahuan baik sejumlah 19 responden (30,6\%), sedangkan responden dengan pengetahuan cukup sebanyak 21 responden $(33,9 \%)$. Pengetahuan merupakan hasil dari tahu dan ini terjadi setelah orang melakukan penginderaan terhadap suatu obyek tertentu. ${ }^{8}$ Pengetahuan ibu hamil TM III tentang tanda bahaya kehamilan merupakan kemampuan ibu hamil TM III untuk mengetahui hal - hal yang berkaitan dengan tanda bahaya kehamilan. Tingkat pengetahuan ibu hamil sangat berpengaruh terhadap kemampuan ibu untuk menyerap informasi dan memahami tentang tanda bahaya kehamilan.

Pengetahuan ibu yang baik dapat disebabkan karena pendidikan responden yang sebagian besar SMA, yakni terdapat 34 reponden $(54,8 \%)$ dan ada 7 responden $(11,3 \%)$ yang sudah menempuh perguruan tinggi. Hal tersebut sesuai dengan teori yang mengatakan bahwa faktor yang mempengaruhi pengetahuan salah satunya adalah pendidikan. ${ }^{8}$ Tingkat pendidikan seseorang berpengaruh dalam memberi respon yang berasal dari luar. Orang yang berpendidikan akan memikirkan kembali setiap tindakannya. Tingkat pendidikan merupakan upaya yang dilakukan untuk memberikan pengetahuan sehingga terjadi perubahan perilaku yang meningkat.

Pendidikan ibu yang tinggi menunjang ibu untuk mengetahui lebih banyak informasi tentang tanda bahaya kehamilan. Ibu yang berpendidikan tinggi akan lebih banyak mencari tahu tentang kehamilannya, sehingga pengetahuan ibu tentang tanda bahaya kehamilanpun meningkat. Setelah ibu mengetahui tentang tanda bahaya kehamilan, diharapkan ibu dapat memanfaatkan buku KIA dan ibu dapat mendeteksi secara dini komplikasi ataupun tanda bahaya yang ada di dalam dirinya secara mandiri sehingga tanda bahaya kehamilan dapat segera terdeteksi dan dapat dilakukan penanganan yang tepat.

Pendidikan ibu yang baik juga dapat dipengaruhi oleh status gravida ibu, ditunjukkan dengan responden yang memiliki status multigravida sebanyak 38 responden $(61,3 \%)$. Ibu multigravida telah memiliki pengalaman pada kehamilan pertama mereka sehingga sudah tidak asing dengan buku KIA. Hal ini sesuai dengan teori bahwa pengalaman merupakan salah satu faktor yang mempengaruhi pengetahuan. Pengetahuan dapat diperoleh dari sesuatu yang pernah dilakukan seseorang yang bersifat nonformal. Pengalaman individu dapat berasal dari lingkungan kehidupannya. ${ }^{8}$

Tidak menutup kemungkinan bahwa responden primigravida juga mempunyai pengetahuan yang baik karena pendidikan formal mereka ataupun pengalaman keluarga ataupun teman - teman disekitarnya yang ia gali informasinya karena sebagian besar pengetahuan diperoleh melalui mata dan telinga.

Responden yang memiliki pengetahuan kurang yakni berjumlah 22 responden (35,5\%). Hal ini dapat terjadi karena masih ada ibu yang mempunyai pendidikan terakhir SD, yaitu ada 13 responden (21\%). Semakin rendah pendidikan seseorang semakin sulit untuk menerima informasi yang diberikan. sehingga dalam menyampaikan informasi tentang tanda bahaya kehamilan digunakan cara penyampaian yang lebih sederhana agar ibu hamil dapat menerima dan memahami informasi yang disampaikan. Ibu hamil juga dapat bertanya tentang hal - hal yang tidak dipahami kepada 
bidan sehingga dapat meningkatkan pengetahuan ibu hamil dengan pendidikan rendah.

Selain dari tingkat pendidikan, pengetahuan yang rendah juga disebabkan karena kurangnya pengalaman ibu karena kehamilan ini merupakan pengalaman pertama bagi ibu. Ibu yang berstatus primi gravida yakni ada 24 responden $(38,7 \%)$. Pengetahuan yaitu menggunakan data secara maksimal disertai dengan kemampuan ketrampilan kompetensi, ide, intuisi, komitmen dan motivasi orang orang yang terlibat. ${ }^{9}$

Pengetahuan dapat dipengaruhi oleh banyak faktor, salah satunya yaitu informasi. Ibu yang kurang mendapatkan informasi akan juga akan memiliki pengetahuan yang kurang. Semakin banyak informasi yan diterima semakin baik pula pengetahuan ibu. Sebenarnya saat pertama kali mendapatkan buku KIA, sebagian besar bidan telah menjelaskan kepada ibu isi dari buku KIA tersebut. Sebagai modal awal ibu dalam memahami isi dari buku KIA. Namun, kurang minatnya ibu akan buku KIA sehingga menyebabkan pengetahuan ibu tentang tanda bahaya kehamilanpun kurang atau tidak banyak. $^{8}$

Pengetahuan selalu berubah - ubah sesuai dengan perkembangan zaman. Bentuk pengetahuan memungkinkan untuk dapat diubah, yang saat ini tacit (ada di kepala orang) menjadi pengetahuan yang explicit (dimodifikasi dan diekspresikan sebagai informasi di dalam database, dokumen, dan lain - lain) ataupun sebaliknya. $^{9}$

Berdasarkan data dari 62 responden, sebagian besar responden telah memanfaatkan buku KIA, yakni sebanyak 42 responden $(67,7 \%)$. Buku KIA merupakan salah satu instrumen pelayanan kesehatan ibu dan anak yang diterima langsung oleh ibu dan keluarga. Penggunaan buku KIA ini merupakan salah satu langkah strategis untuk meningkatkan kemandirian serta peran serta masyarakat di bidang kesehatan khususnya ibu dan anak. Ibu hamil dapat dengan memudahkan mendapatkan informasi yang berkaitan dengan kehamilannya. Buku KIA juga dapat membantu bidan untuk memantau kehamilan ibu. Penting sekali untuk membaca dan menerapkan apa yang ada didalam buku KIA tersebut. Peran lini depan dibawah kewenangan pemerintah daerah sangat mempengaruhi keberhasilan penerapan buku KIA ini. ${ }^{2}$

Pemanfaatan buku KIA dapat dipengaruhi oleh beberapa faktor salah satunya yaitu tingkat pendidikan ibu. Fakta dilapangan, responden sebagian besar berpendidikan SMA 34 responden $(54,8 \%)$ dan ada responden yang sudah menempuh perguruan tinggi yakni ada 7 responden $(11,3 \%)$. Hal tersebut sesuai dengan pendapat Green, bahwa yang mendasari timbulnya perilaku yaitu pengetahuan yang didalamnya terdapat tingkat pendidikan. Diharapkan semakin tinggi tingkat pendidikan, banyak ibu hamil yang memanfaatkan buku KIA. ${ }^{8}$

Pemanfaatan buku KIA juga dapat dipengaruhi oleh status multigravida. Dapat dilihat dari sebagian besar responden yang berstatus multi gravida yakni sebanyak 38 responden $(61,3 \%)$. Hal ini disebabkan karena ibu multigravida sudah mempunyai pengalaman pada kehamilan pertamanya. Selain itu Budaya masyarakat juga sangat mempengaruhi pemanfaatan buku KIA. Sebagian masyarakat mengangggap bahwa hamil merupakan sesuatu yang dianggap wajar dan hal yang normal sehingga menurut mereka, pemeriksaan kehamilan bukan suatu hal yang harus dikerjakan.

Pada tabel 6. masih didapatkan responden yang kurang memanfaatkan buku KIA, yakni berjumlah 20 responden (32,3\%). Sedangkan responden yang berstatus primigravida yakni ada 24 responden $(38,7 \%)$. Ibu primigravida belum memiliki pengalaman, sehinga mereka kurang mengetahui hal - hal yang berkaitan dengan kehamilannya. Dengan adanya buku KIA memudahkan ibu hamil dalam mendapatkan informasi kesehatan tentang kehamilannya yang meliputi pemeriksaan kehamilan, kelas ibu hamil, nutrisi bagi ibu hamil, persiapan melahirkan, gizi ibu hamil, tanda bahaya kehamilan dan masalah lain pada masa kehamilan. Buku ini dapat dibawa pulang oleh ibu sehingga ibu dapat membacanya di rumah. Namun masyarakat masih kurang 
memahami betapa pentingnya membaca buku KIA. Ibu hamil beranggapan bahwa buku KIA hanya digunakan sebagai kontrol saat iu memeriksakan kehamilannya tanpa mau membacanya di rumah.

Buku KIA dapat dimanfaatkan oleh ibu dan keluarga dengan cara membaca dan memahami buku KIA ibu dapat bertanya kepada bidan atau tenaga kesehatan lain tentang hal-hal yang tidak dipahami dari isi buku KIA tersebut. Pemanfaatan buku KIA dapat diamati dari kepemilikan buku KIA, ibu membawa saat ke fasilitas kesehatan, membaca informasi kesehatan di dalam buku KIA menjadi determinan yang penting bagi pengetahuan ibu.

Pemanfaatan buku KIA juga didukung oleh faktor - faktor lain seperti sikap dan perilaku petugas kesehatan yang memberikan intervensi yang akan membentuk perilaku masyarakat. ${ }^{8}$ Penggunaan buku KIA merupakan salah satu strategi pemberdayaan masyarakat terutama keluarga untuk memelihara kesehatana dan upaya mendapatkan pelayanan yang berkualitas dan sesuai dengan standar. Buku KIA juga berisi informasi, catatan maupun pesan penting yang dibutuhkan ibu haml dan intervensi yang harus dilakukan berdasarkan kondisi ibu hamil, sehingga dapat memudahkan ibu hamil mengingat intervensi yang harus dilakukan.

Pengetahuan ibu hamil TM III tentang tanda bahaya kehamilan terdapat 19 responden (30,6\%) yang berpengetahuan baik dan 21 responden $(33,9 \%)$ berpengetahuan cukup. Dari 40 responden tersebut terdapat 26 responden yang memanfaatkan buku KIA dan 14 responden kurang memanfaatkan buku KIA. Pemanfaatan buku KIA merupakan suatu perilaku, dan perilaku terebut dapat dipengaruhi oleh pengetahuan. Pengetahuan merupakan hasil dari tahu dan ini terjadi setelah orang melakukan penginderaan terhadap suatu objek tertentu. Pengetahuan atau kognitif merupakan domain yang sangat penting dalam membentuk tindakan seseorang. ${ }^{8}$

Pengetahuan akan mempengaruhi tindakan seseorang. Salah satu tingkatan pengetahuan adalah aplikasi, yaitu kemampuan seseorang dalam menguasai dan menggunakan materi yang sudah dipelajari dalam situasi dan kondisi yang sebenarnya. Aplikasi disini perilaku kesehatan yang terdapat di dalam buku KIA yang telah dibaca oleh ibu hamil difahami dan mampu diterapkan. Dengan pengetahuan yang baik, ibu hamil akan lebih mudah memahami isi dari buku KIA dan mau menerapkan apa yang ada di dalam buku tersebut.

Responden yang memiliki pengetahuan kurang terdapat 22 responden $(35,5 \%)$ dengan 16 responden memanfaatkan buku KIA dan 6 responden kurang memanfaatkan buku KIA. Meskipun berpengetahuan kurang, banyak responden yang sudah memanfaatkan buku KIA, hal ini terjadi karena pemanfaatan buku KIA tidak hanya dipengaruhi oleh pengetahuan tentang tanda bahaya kehamilan saja, dapat dipengaruhi juga oleh pengetahuan tentang pentingnya pemeriksaan kehamilan, nutrisi ibu hamil, dan sebagainya, ataupun dipengaruhi oleh faktor - faktor lain, salah satu faktor yang mempengaruhi pemanfaatan buku KIA yaitu sikap masyarakat terhadap kesehatan tradisi dan kepercayaan masyarakat akan hal-hal yang berkaitan dengan kesehatan sistem nilai yang dianut oleh masyarakat tingkat pendidikan, tingkat social, ekonomi dan sebagainya. Pemanfaatan buku KIA juga didukung oleh faktor - faktor lain seperti sikap dan perilaku petugas kesehatan yang memberikan intervensi yang akan membentuk perilaku masyarakat. ${ }^{8}$

Ibu hamil bisa mendapatkan informasi tentang tanda bahaya kehamilan dari petugas kesehatan internet, buku, keluarga, taupun tetangga. Tanda bahaya kehamilan penting untuk diketahui, karena dapat menyebabkan kematian pada ibu maupun janinnya, sehingga perlu dilakukan perawatan khusus dan pemantauan secara ketat bagi ibu hamil yang ditemukan adanya tanda bahaya kehamilan pada kehamilannya.

Dengan membaca buku KIA, ibu hamil dapat mengerti dan memahami informasi yang ada di dalam buku KIA sehingga isi buku KIA tersebut dapat diterapkan dan ibu mau memeriksakan kehamilannya di berbagai fasilitas kesehatan kapan saja dan dimana saja sehingga kehamilan ibu tetap terpantau tenaga 
kesehatan. Dibutuhkan kesadaran para ibu hamil untuk membaca buku KIA maupun membawa buku KIA saat melakukan pemeriksaan difasilitas pelayanan kesehatan.

Penerapan buku KIA pada semua fasilitas kesehatan diharapkan dapat meningkatkan pengetahuan dan pemahaman ibu hamil tentang tanda bahaya kehamilan sehingga komplikasi yang mungkin terjadi dalam masa kehamilan dapat terdeteksi sedini mungkin sesuai dengan tujuan pelayanan antenatal yaitu untuk mencegah adanya komplikasi obstetri dan memastikan bahwa komplikasi dapat diteksi dan dapat segera ditangani. ${ }^{10}$

Buku KIA sangat penting, karena dalam buku tersebut tercatat informasi yang berguna sebagai panduan ibu hamil dalam merawat kehamilannya sampai anaknya lahir. Selain itu tercantum catatan perkembangan kesehatan kehamilan yang diisi oleh petugas kesehatan yaitu bidan pada saat ibu memeriksakan kehamilan.

\section{SIMPULAN DAN SARAN}

Berdasarkan hasil penelitian mengenai hubungan hubungan antara pengetahuan ibu hamil TM III tentang tanda bahaya kehamilan dengan pemanfaatan buku KIA dapat disimpulkan bahwa :

a. Tingkat pengetahuan ibu hamil TM III tentang tanda bahaya kehamilan di wilayah Puskesmas Sumbersari hampir setengahnya mempunyai pengetahuan kurang.

b. Pemanfaatan buku KIA oleh ibu hamil TM III di wilayah Puskesmas Sumbersari sebagian besar telah memanfaatkan buku KIA.

c. Tidak ada hubungan antara pengetahuan ibu hamil TM III tentang tanda bahaya kehamilan dengan pemanfaatan buku KIA di wilayah Puskesmas Sumbersari

Ibu hamil TM III sebaiknya dapat menggunakan informasi yang didapat tentang tanda bahaya kehamilan dan pemanfaatan buku KIA sebagai pengetahuan mereka dan masyarakat menyadari akan pentingnya membaca buku KIA sebagai sumber pengetahuan mereka.

\section{UCAPAN TERIMA KASIH}

Peneliti mengucapkan terima kasih kepada semua pihak yang telah membantu terselesaikannya penelitian ini, baik pada saat proses permohonan ijin penelitian dan saat pengambilan data penelitian.

\section{REFERENSI}

1. Kementerian Kesehatan Republik Indonesia. 2016. http://www.depkes.go.id/ resources/ download/pusdatin/profil-kesehatanindonesia/Profil- Kesehatan-Indonesia-2016.pdf.

2. Mulati, E., Widyaningsih, Y. dan Royati, O. F. (ed.) 2015. Buku Ajar Kesehatan Ibu Dan Anak. Jakarta Selatan

3. MOH. 2009. "Pedoman Umum Manajemen Penerapan Buku KIA," hal. 28.

4. Badan Penelitian dan Pengembangan Kesehatan .2013. "Riset Kesehatan Dasar (RISKESDAS) 2013," Laporan Nasional 2013, hal. 1-384. doi: 1 Desember 2013.

5. Badan Penelitian dan Pengembangan Kesehatan .2007. "Riset Kesehatan Dasar (RISKESDAS) 2007," Laporan Nasional 2007

6. Dinas Kesehatan Kabupaten Jember. 2017. "Profil Kesehatan Kabupaten Jember Tahun 2016."

7. Orientasi, P. dan Kia, B. 2008. Buku KIA.

8. Notoatmodjo, S. 2003. Pendidikan Dan Perilaku Kesehatan. Jakarta: Rineka Cipta.

9. Kusumadmo, E. 2013. Manajemen Strategik Pengetahuan. Yogyakarta: Cahaya Atma Pustaka.

10. Prawirohardjo, S. 2006. Buku Acuan Nasional, Pelayanan Kesehatan Maternal Dan Neonatal. Keempat. Diedit oleh A. B. Saifuddin. Jakarta: Yayasan Bina Pustaka Sarwono Prawirohardjo. 